International

Public

Management

Journal

\title{
POLITICS, PRINCIPAL-AGENT PROBLEMS, AND PUBLIC SERVICE MOTIVATION
}

\author{
SEAN GAILMARD \\ UNIVERSITY OF CALIFORNIA BERKELEY
}

\begin{abstract}
In this essay I make two related points about public service motivation. First, despite advances in public service motivation measurement at the level of individuals, little is known about the channels by which organizations develop a workforce comprised of people with high levels of PSM. I discuss recent political science scholarship suggesting that this development is endogenous to both personnel policies and the political position of bureaucratic agencies. Second, I contend that PSM in a workforce is useful at an organizational level primarily because it helps in mitigating or "solving" specific principal-agent problems, though it can also intensify others.
\end{abstract}

In the last twenty years public service motivation (PSM) has emerged as an important area of research in public administration and personnel management. Advances have been made in the study of variation in PSM among individuals, particularly in the development of survey instruments to measure PSM and tracing out its antecedents. Yet in other important areas knowledge of PSM remains cursory or nonexistent. In this brief essay I will discuss two closely related areas: the development of high PSM among employees of public organizations, and the effects of PSM on bureaucratic performance and public policy. My principal argument in this essay is that the degree of PSM in public bureaucracies depends on a combination of personnel policies structuring public service employment, and the role of public bureaucracies in the policy process. In brief, I build on prior research arguing that one way for organizations to be staffed by individuals with high levels of PSM is to induce such individuals to opt into public service (Perry and Wise 1990; Paarlberg, Perry, and Hondeghem 2008; Perry, Hondeghem, and Wise 2009). By situating public bureaucracies in the political process, I trace out an implication of this argument, that PSM helps to mitigate certain principal-agent problems endemic in bureaucratic policymaking, but that it can also intensify others. Viewed as such PSM is a means to an end. 


\section{THE DEVELOPMENT OF PUBLIC SERVICE MOTIVATION AT THE ORGANIZATIONAL LEVEL}

Perry and Wise $(1990,368)$ defined public service motivation as "an individual's predisposition to respond to motives grounded primarily or uniquely in public institutions." Perry (1996) further decomposed PSM into four dimensions: attraction to public policymaking, commitment to the public interest and civic duty, compassion, and self-sacrifice.

It is apparent from the conceptual definition and empirical measurement of public service motivation that not all individuals are equally endowed with it. Determinants and antecedents of PSM at the individual level have been analyzed in the literature (Perry 1997; Brewer, Selden, and Facer 2000). Given the individual-level variation in PSM, it is not prima facie obvious that public bureaucracies must be populated by actors who possess high levels of it. Prominent examples of bureaucratic corruption and malfeasance both in the United States and abroad are sufficient to demonstrate the empirical relevance of this point: it is difficult to contend that recent scandals relating to bribes in the distribution of mineral rights on public lands by the U.S. Department of Interior reveal a high degree of public service motivation on the part of perpetrators.

While some factors have been identified that lead individuals to achieve high ratings on PSM measurement scales, little attention has been devoted to how organizations can develop high PSM in their ranks or attract individuals with high levels of PSM. Furthermore, recent work that does explore organizational determinants of PSM (Moynihan and Pandey 2007; Paarlberg, Perry, and Hondeghem 2008) focuses on internal management practices within public organizations, for example, mission statements, internal "red tape," and degree of hierarchy. Excluded from this research is the issue of the political environment surrounding public organizations. Given the presumed importance of PSM in fostering successful public service delivery, this is an important missing link in the literature.

In general there are two paths public organizations can take to cultivate high PSM in their work force: organizations can select individuals who already possess high PSM, and they can inculcate high PSM among individuals who happen to work for the organization. Little is known about either mechanism-how it works at a causal level, how and why it developed in specific cases, etc.

Gailmard and Patty (2007) develop a formal model related to the first channel. The model formalizes two aspects of public service motivation as identified in the PSM literature: a process of self-selection into a public bureaucracy by potential bureaucrats, and individual heterogeneity in degree of PSM. Self-selection helps to endow organizations with a high PSM workforce. The central point of the model is that this self-selection has several beneficial consequences from the standpoint of organizational capacity and effectiveness, but the same self-selection also inherently contributes to politicization of bureaucratic policymaking. Thus, the attraction and self-selection of public servants is a double-edged sword, though the PSM literature has focused only on one of the edges.

A basic presumption of this model is that individuals vary in the extent to which they are concerned with public policy, a presumption firmly bolstered by individual-level 
survey evidence (G. Lewis and Frank 2002). Some agents attach intrinsic concern to public policy in the sense that they will sacrifice other important goals to improve it; they are "policy motivated." For other agents in the model, utility is not affected by public policy; these agents are labeled "policy indifferent" in the model's parlance. While intentionally stark and dichotomous, this distinction maps directly into Perry's (1997) first dimension of PSM, attraction to public policymaking. Arguably, though, there are differences in the concepts. Literally construed, Perry's dimension is specifically public policy making in and of itself - so that simply participating in the process, no matter what policies it leads to, is sufficient to tap into this motivation. In Gailmard and Patty's model, policy-motivated individuals obtain benefits if they consider policy desirable, but also incur costs if they consider it undesirable. They obtain these benefits and costs regardless of whether they participate in the process or are otherwise ordinary citizens engaged in private sector employment. Moreover, policy-motivated agents in Gailmard and Patty's model obtain benefits from effecting what they consider positive changes in public policy by participating in the process. Thus it is not simply participation in the process that matters to these agents, but participation in furtherance of desirable ends. This assumption squares naturally with Paarlberg and Perry's (2007) finding that public servants exhibit greater "buy in" to organizational goals when they fall within the servant's "zone of (affective and normative) values," as well as the general observation that it is manifestly contrary to a public service ethic for an agent to use public authority to further policies that she herself considers to be detrimental by her own standards of good policy. This is perhaps so self-evident that Perry (1997) left it implicit in his characterization of PSM.

Importantly, public policy in Gailmard and Patty's model implicitly deals with one policy issue or a bundle of related issues. This is the sort of bundle of issues or policy areas that might fall within the jurisdiction of a specific bureaucratic agency such as the National Labor Relations Board or the Securities and Exchange Commission. When individuals are "policy motivated," therefore, they attach importance to the bundle of policy areas within the purview of a specific agency. This does not force them to care exclusively about this bundle of issues, or preclude them from caring about others. Rather it is an assumption tailored to the fact that government agencies carve the giant landscape of public policy into smaller parcels, and in pursuing public service, individuals can only till a limited number of parcels at a time.

In addition, individual agents in Gailmard and Patty's model model vary according to the specific public policies they find most desirable. This variation is captured in a spatial model of policy making, in which individuals have varying "ideal points" or most desired policies. The "space" of available policies is defined by an ordering of policies with respect to each other and a metric to specify whether policy $A$ is nearer to policy $B$ or $C$. At a general level the ordering of policies in the space falls along a liberal-conservative continuum. Thus, an individual's ideal policy is associated with the liberalism/conservatism of an individual's stance on a policy issue. In Gailmard and Patty's model, though squarely in the "rational choice" camp, there is no overt or hidden link between an individual's ideal policy and the policy that best suits their own self interest, economic or otherwise. Rather the model, like spatial models in general, is agnostic about the source of agent preferences over public 
policy. The content of these preferences could stem only from the individual agent's conception of good public policy, or vision of a just social order, or ideals of the public interest, and so forth. The critical assumption in the model is that potential public servants have policy preferences of their own and cannot check them at the door when they enter public service. ${ }^{1}$

In Gailmard and Patty's model agents must decide whether to opt into employment in a public bureaucracy or pursue more remunerative employment elsewhere (e.g., the private sector). A central finding of the model is that under specific conditions, those who have greater concern for public policy are disproportionately likely to self-select into public service. The reason is that public employment offers the potential (though not the certainty) to affect public policy, while outside employment does not. When the political environment of the bureaucracy allows this potential to be actualized, policy-motivated agents find public service valuable because it uniquely affords the opportunity to advance causes they consider important. When this happens, public servants are dedicated to developing expertise on the substantive and procedural details of public policy as well as the capacity to implement policy effectively. Picking up from the literature on statutory discretion in bureaucracies (Epstein and O'Halloran 1999; Huber and Shipan 2002), in our model politicians in turn respond to this expertise development by granting policy discretion to public bureaucracies (or, at least, greater discretion than the bureaucracy would have without this expertise). Because of this response by politicians, bureaucrats participate in the policy process and help shape exactly what public policy is. Thus, given that agency discretion is determined in a political process, a political response, not just internal organizational practices, plays an important role in unleashing the powerful beneficial effects of PSM.

Therefore, in Gailmard and Patty's framework, opting into public service and developing substantive and procedural expertise is its own reward for policymotivated agents. In a sense, the concern that these agents have for public policy implies that policy discretion conditioned on their expertise development is a form of compensation. It is a compensation that is uniquely available in public service, and it is only policy-motivated agents who value it. Agents with less intrinsic concern for public policy or with greater value for the pecuniary returns of private sector employment select out of public service because they do not internalize the benefits of this unique aspect of public service.

In this way Gailmard and Patty's model explicates how individuals with high levels of interest in public policy come to predominate public service employment. However, such individuals bring to the table their own ideals and conceptions of good public policy and the appropriate means to pursue socially desirable results. Policy-motivated agents who self-select into public service cannot realistically be asked to abandon their ideals in the process. It is the very prospect of pursuing these ideals that motivates such individuals to opt into public service in the first place.

It is not a foregone conclusion that this result will occur in the model. An important precondition is that civil service protections and relatively secure tenure are institutionalized in the bureaucracy. The reason is that the development of bureaucratic expertise and capacity is a long-term process. Under a regime of patronage and 
job rotation in bureaucracies, the short-term orientation forced on bureaucrats does not provide sufficient time for expertise investments to "pay off." In the starkest scenario these investments are therefore simply not made by public servants. This sets off a vicious cycle in which politicians do not respond by granting policy discretion. Policy-motivated agents, in this scenario, do not face any particular incentive to self-select into public service.

\section{THE VALUE OF PUBLIC SERVICE MOTIVATION}

The logic outlined above clarifies several respects in which public service motivation is useful in bureaucracies from the standpoint of the "public interest" as well as public management. First, PSM allows public organizations to staff themselves with dedicated, talented individuals at lower cost than they would be able to find if PSM did not exist. This is because the ability to work on what they understand as the important mission of public organizations is a form of compensation for individuals with high levels of PSM. For instance, in the logic sketched above, policy-motivated agents forego greater compensation from other employment to pursue the policy goals they value. Only policy-motivated agents do this because only they are willing to substitute the pursuit of policy goals for material compensation.

Second, PSM leads individuals who select into public service to develop substantive and procedural expertise on the issues within their purview. This is because such expertise is met with expanded policy discretion, and policy-motivated individuals value the ability to use this discretion to effect what they understand to be beneficial changes in public policy. PSM therefore provides an incentive for public servants to develop substantive and procedural expertise, even if it is costly. In this sense, PSM works as an incentive payment for expertise development, but only for individuals attracted to public policymaking. When bureaucratic expertise must be developed, inducing agents to invest in it is simply another facet of a principal-agent problem, and PSM helps to overcome it. If public servants did not care intrinsically about being able to use expertise to effect desirable changes in policy and its implementation, the government would have to rely more heavily on other, extrinsic incentives to induce them to cultivate expertise.

Taken together these points suggest that public service motivation helps the government solve specific principal-agent problems it faces with the pool of potential public servants. These problems may involve "hidden information" (loosely, adverse selection), or private information that agents hold about their (exogenous) characteristics. Or they may involve "hidden actions" (loosely, moral hazard), or (endogenous) actions taken by agents that are not subject to explicit contracting by principals. For instance, self-selection of diligent, hard-working individuals into the bureaucracy addresses a hidden information problem; the problem assumes a relatively stable, exogenous trait - loosely, diligence - and PSM provides one means by which governments can economize on the problem of identifying diligent individuals. Alternatively, cultivating policy discretion by way of expertise investment addresses a hidden actions problem. The problem assumes that it is difficult for governments to write contracts around how hard agents work to develop new expertise (even if agents 
are required to undergo specific training, how much they internalize or absorb is not contractable), and PSM provides an incentive for agents to apply themselves vigorously. In either case, the logic identified here shows that PSM is useful as a means to an end of alleviating agency problems.

This is an extension of a line of argument PSM scholars recognize when they discuss the job performance or effort implications of PSM (Alonso and G. Lewis 2001; Frank and G. Lewis 2004). Probably the paradigmatic principal-agent problem relating to public bureaucracy that is most familiar to public administrationists is the problem of "shirking." That is, if bureaucrats are effort-averse and selfinterested (Niskanen 1971), political supervisors face a moral hazard problem because bureaucrats will not exert themselves to produce levels or quality of public service sought by political supervisors. Merit pay is one device to solve this problem, and PSM advocates contend it is another, substitute approach (they are probably not complementary if PSM is "crowded out" by extrinsic incentives). PSM alleviates the moral hazard problem by bringing in individuals who want to work on the mission of a public organization and are self-sacrificing or altruistic (Le Grand 2003). The argument above is simply a recognition that there is not just one grand principal-agent problem in bureaucracy, but many overlapping ones. PSM is useful in management to the extent that it helps resolve these problems.

\section{THE LIMITS OF PUBLIC SERVICE MOTIVATION}

PSM research has debated whether PSM actually exists, whether the attractionselection-attrition cycle works as hypothesized, and whether PSM affects job performance. But apart from these questions it can be asked whether PSM is on balance beneficial, either from the standpoint of public interest or public management.

The formal logic sketched above suggests that while PSM helps to solve some principal-agent problems, it does so at the cost of introducing or intensifying others. Specifically, concern for public policy implies that public servants with high levels of PSM bring their own policy concerns to the table. This is a corollary of the individual self-selection discussed above. We should not expect individuals attracted by PSM considerations to the Environmental Protection Agency, Equal Employment Opportunity Commission, Occupational Safety and Health Administration, or Federal Bureau of Investigation to be a random cross-section of potential public servants when it comes to their concern for the issues within the purview of these organizations. Rather, one of the reasons why work in the EPA (for instance) would be intrinsically rewarding is because an agent considers environmental protection to be particularly intrinsically important. Put differently, if individuals vary not just in their attraction to public policymaking in general, but also in the importance they attach to specific policy areas, then the set of public servants in a particular bureaucratic agency should be expected not just to have high levels of general PSM, but high levels of issue-specific motivation as well (Brehm and Gates 1997). Even if there is a single, unitary, universal form of PSM (but see Koehler and Rainey 2008), the formal logic sketched above suggests that it is the interaction of this generalized PSM and concerns specific to the policy areas in the purview of a specific 
organization that allows individuals to actualize the unique potential value of public service, and thus will induce individuals to self-select into it. The issue is one of fit between person and organizational environment, an issue that PSM research is only beginning to tap (Bright 2008; Leisink and Steijn 2008). Moreover, PSM may inherently be associated with distinct political attitudes and ideologies in general, not just specific to the particular issues addressed by a particular organization or agency. Perry (1997) provides some general evidence on this point. In survey responses he finds (Exhibit 3) that liberal political attitudes are associated with both attraction to public policymaking and propensity for self-sacrifice, two of his four primary dimensions of PSM.

Divergence in attitudes and values highlights a point that is latent and at best implicit in the PSM literature: by bringing values into public service, PSM brings value conflict, and therefore politics, into public management as well. First, the value conflict. As Paarlberg and Perry (2007) show, public servants do not subvert their own values and altruistically accept whatever values an organization hands to them; instead their acceptance of organizational missions depends on whether they fall in the individual's "zone of values." Brehm and Gates (1997) find that conflicting values between agents and organizations reduce work effort. Bright (2008) finds that person-environment fit - which includes the congruence of individual and organizational goals and values - affects intent to remain in public service more than a generalized, non-organizationally-specific PSM.

A corollary of this is that if and when the normative and affective values of public servants (and their organizations) conflict with the values privileged or pursued by politicians, value conflict is part of the story of public management. The reason is that no values are politically neutral. They can conflict with values held by other actors, equally noble and worthy. Discussions of whether PSM is partly about altruism or whether public servants are more altruistic than private sector counterparts (Le Grand 2003) are beside this point. Concretely, individuals who opt for a life of public service in pursuit of environmental protection, workplace safety, or rights of laborers may be altruistic and self-sacrificing, but there is no reason to expect them to have the same vision of good public policy as elected officials (cf. Aberbach and Rockman 2000; Maranto and Hult 2004). There is every reason to expect that politicians will not alter their vision of good public policy, whatever values may inform it, simply because altruistic bureaucrats believe a differen course is warranted.

Second, politics enters the public management picture when these value conflicts are sorted out in a collective decision. Value conflict between public servants and political actors is the source of some of the paramount principal-agent problems politicians face with the bureaucracy. For instance, this value conflict is the reason why classical formulations of administrative accountability (see, e.g., Landis 1938) - find expert agents who would do the same things the relevant principals would do, if they were as informed as the agents - are politically problematic. Since agents possess not only expertise but their own visions and ideals for good policy, it is difficult to ensure that agents apply their expertise only in pursuit of the goals of principals. This is a classic principal-agent problem: it is a strategic dilemma that exists because one party takes an action on behalf of another party who for some reason cannot take it herself, 
and the latter party is not sure the former will act entirely in her interest rather than his own. Nor does this problem rest on an assumption of bureaucratic malfeasance, shirking, or repudiation of law commonly identified with principal-agent models in particular, or rational choice in general. Rather, public servants are assumed in this framework to care and to be willing to sacrifice personally to achieve what they care about socially: It is values, and concern about which values will predominate when policy cannot accommodate all, that drive the conflict.

Unlike formulations of the principal-agent problem familiar in public administration, including a canonical one underlying economic models of incentive pay, these sorts of political agency problems are not naturally solved with pecuniary incentives offered by principal to agent. But in recognizing such dynamics as engendering a principal-agent problem is beside the point; it simply means that political principals will use other channels or organizational structures to ensure that agents in public service will not favor their own values over those espoused by political principals. Though the means are different from standard (introductory) textbook principalagent problems, the impetus and ends are the same: ensuring that public servants train their talents on the achievement of values sought by political principals. A variety of possibilities exist depending on the level of and branch of government - recent work has explored the administrative law environment of agencies and procedural constraints (McCubbins, Noll, and Weingast 1987); statutory specificity (Epstein and O'Halloran 1999; Huber and Shipan 2002; Gailmard 2002, 2009b); legislative oversight (Gailmard 2009a); more and deeper reliance by presidents on political appointees to manage programs (D. Lewis 2007); and regulatory review (Wiseman 2009). In short, value conflict will affect the degree of discretion public servants have to pursue their missions and act on their values, because that discretion is determined in a political process. Some or all of these "solutions" to the principal-agent problem so created may compromise public management; managers may recognize them as the flip side of "micromanagement" and political meddling.

Public service motivation helps to create these principal-agent problems by inducing individuals with specific value commitments to select into public service. This is the other edge of the PSM sword. Public service encourages people to pursue their affective and normative values in their work, but value commitments differ among actors in the policy process. Consequently, a necessary result of public service motivation and the attraction and self-selection it engenders is value conflict among actors in the policy process, and therefore the intrusion of politics into administration.

\section{CONCLUSION}

In this brief article I have made two basic points. First, public service motivation cannot be automatically assumed to exist in public organizations, and it cannot be developed simply by deciding that it should exist. Rather, it is endogenous to the role of bureaucratic organizations in the policy process and the political response to bureaucratic expertise. When politicians reward expertise development in bureaucracies with an enhanced role in policymaking, agents who obtain utility from improving public policy will obtain unique benefits from public service, and self-select into it. 
Second, public service motivation should be viewed instrumentally, as a means to an end, rather than an end in itself. In general terms it is a tool to solve principalagent problems that the public faces with respect to bureaucrats. But, first, it is only one such tool, and second, it is a blade with two edges. As it mitigates some principal-agent problems it has the potential to intensify others.

It is entirely conceivable, then, that the best available solution to the multifaceted bundle of principal-agent problems can in some instances require the use of instruments that "crowd out" PSM. For instance, tightly controlled discretion, "red tape" limiting the freedom of administrative action (policy decisions, budgetary reallocations, etc.), or subjecting career civil servants to greater oversight by political appointees may be dispiriting to public servants. Given the attraction-selection-attrition cycle highlighted in the PSM literature (Crewson 1997; Naff and Crum 1999; Steijn 2008; Bright 2008) this may in turn cause agents with high PSM to opt out of public service, or inhibit the development of PSM among existing public servants, or both. While we should not assume that tools are optimally deployed for the public interest in such cases, nor should we assume that this is inherently problematic. PSM is a means to an end, and it may stand in conflict with other means for more important ends. In this sense, critiquing politicians' approach to bureaucracies on the grounds that it undermines PSM is not by itself a compelling critique. Instead, PSM scholars should focus on maintenance of PSM in environments with high value conflict. An understanding of this situation would allow public organizations to maintain and recruit high-quality employees, thus preserving continuity and quality of services, even when the external environment of the organization makes this challenging. Simply put, we should not expect politics to change to accommodate management needs, so we should try to develop management practice that is robust to challenging politics.

\section{ACKNOWLEDGEMENTS}

The author thanks Donald Moynihan, John Patty, and fellow panelists at the 2008 Meeting of the Midwest Political Science Association for their helpful comments.

\section{NOTE}

1. Thus Gailmard and Patty's model is at odds with the prevailing strain of rational choice work on public bureaucracy familiar to public administrationists; see, e.g., DiIulio 1994. Though it is common in some strands of rational choice, especially those drawn from economics, to equate rationality with self interest, rationality in and of itself requires no such link.

\section{REFERENCES}

Aberbach, J. and B. Rockman. 2000. In the Web of Politics: Three Decades of the U.S. Federal Executive. Washington, DC: Brookings.

Alonso, P. and G. Lewis. 2001. "Public Service Motivation and Job Performance." American Review of Public Administration 31: 363-380. 
Brehm, J. and S. Gates. 1997. Working, Shirking, and Sabotage: Bureaucratic Response to a Democratic Public. Ann Arbor, MI: University of Michigan Press.

Brewer, G. A., S. C. Selden, and R. L. Facer. 2000. "Individual Conceptions of Public Service Motivation." Public Administration Review 60: 254-264.

Bright, L. 2008. "Does Public Service Motivation Really Make a Difference on the Job Satisfaction and Turnover Intentions of Public Employees?" American Review of Public Administration 38: 149-166.

Crewson, P. E. 1997. "Public-Service Motivation: Building Empirical Evidence of Incidence and Effect." Journal of Public Administration Research and Theory 4: 499-518.

DiIulio, J. 1994. "Principled Agents: The Cultural Bases of Behavior in a Federal Government Bureaucracy." Journal of Public Administration Research and Theory 4: 277-318.

Epstein, D. and S. O'Halloran. 1999. Delegating Powers: A Transaction Cost Politics Approach to Policymaking Under Separate Powers. New York: Cambridge University Press.

Frank, S. and G. Lewis. 2004. "Government Employees: Working Hard or Hardly Working?" American Review of Public Administration 34: 36-51.

Gailmard, S. 2002. "Expertise, Subversion, and Bureaucratic Discretion." Journal of Law, Economics, and Organization 18: 536-555.

Gailmard, S. 2009a. "Discretion Rather Than Rules: Choice of Instruments to Constrain Bureaucratic Policy-Making." Political Analysis 17: 25-44.

Gailmard, S. 2009b. "Multiple Principals and Oversight of Bureaucratic Policy-Making." Journal of Theoretical Politics 21: 161-186.

Gailmard, S. and J. Patty. 2007. "Slackers and Zealots: Civil Service, Discretion, and Bureaucratic Expertise." American Journal of Political Science 51: 883-889.

Huber, J. and C. Shipan. 2002. Deliberate Discretion? The Institutional Foundations of Bureaucratic Autonomy. New York: Cambridge University Press.

Koehler, M. and H. G. Rainey. 2008. "Interdisciplinary Foundations of Public Service Motivation." Pp. 33-55 in J. Perry and A. Hondeghem, eds., Motivation in Public Management: The Call of Public Service. Oxford: Oxford University Press.

Landis, J. M. 1938. The Administrative Process. New Haven, CT: Yale University Press.

Le Grand, J. 2003. Motivation, Agency, and Public Policy: Of Knights and Knaves, Pawns and Queens. Oxford: Oxford University Press.

Leisink, P. and B. Steijn. 2008. "Recruitment, Attraction, and Selection." Pp. 118-135 in J. Perry and A. Hondeghem, eds., Motivation in Public Management: The Call of Public Service. Oxford: Oxford University Press.

Lewis, D. 2008. The Politics of Presidential Appointments. Princeton, NJ: Princeton University Press.

Lewis, G. and S. Frank. 2002. "Who Wants to Work for the Government?" Public Administration Review 62: 395-404.

Maranto, R. and K. M. Hult. 2004. "Right Turn? Political Ideology in the Higher Civil Service, 1987-1994." American Review of Public Administration 34: 199-222.

McCubbins, M., R. Noll, and B. Weingast. 1987. "Administrative Procedures as Instruments of Political Control." Journal of Law, Economics, and Organization 3: 265-300.

Moynihan, D. and S. Pandey. 2007. "The Role of Organizations in Fostering Public Service Motivation." Public Administration Review 67: 40-53.

Naff, K. C. and Crum, J. 1999. "Working for America: Does Public Service Motivation Make a Difference?" Review of Public Personnel Administration 19: 5-16.

Niskanen, W. 1971. Bureaucracy and Representative Government. Chicago: Aldine Atherton.

Paarlberg, L. and J. Perry. 2007. "Values Management: Aligning Employee Values and Organizational Goals." American Review of Public Administration 37: 387-408. 
Paarlberg, L., J. Perry, and A. Hondeghem. 2008. "From Theory to Practice: Strategies for Applying Public Service Motivation.” Pp. 286-293 in J. Perry and A. Hondeghem, eds., Motivation in Public Management: The Call of Public Service. Oxford: Oxford University Press.

Perry, J. 1997. “Antecedents of Public Service Motivation.” Journal of Public Administration Research and Theory 7: 181-197.

Perry, J., A. Hondeghem, and L. Recascino Wise. 2009. Revisiting the Motivational Bases of Public Service. Paper presented at the International Public Service Motivation Research conference, Indiana University, Bloomington, IN, June 7-9.

Perry, J. and L. Wise. 1990. "The Motivational Bases of Public Service." Public Administration Review 50: 367-373.

Wiseman, A. 2009. "Delegation and Positive Sum Bureaucracies." Journal of Politics 71: 998-1014.

\section{ABOUT THE AUTHOR}

Sean Gailmard (gailmard@berkeley.edu) is Assistant Professor in the Charles and Louise Travers Department of Political Science at University of California Berkeley. 